\title{
Aproveitamento do melaço e vinhaça de cana-de-açúcar como substrato para produção de biomassa protéica e lipídica por leveduras e bactéria
}

\section{Use of sugar cane molasses and vinasse for proteic and lipidic biomass production by yeast and bacteria}

\author{
Marcia Luciana Cazetta ${ }^{1}$; Maria Antonia Pedrine Colabone Celligoi ${ }^{2}$
}

\begin{abstract}
Resumo
Este trabalho avaliou a capacidade de crescimento e síntese de lipídeos e proteínas por Saccharomyces cerevisiae, Rhodotorula mucilaginosa, Cândida lipolytica, uma levedura isolada das lagoas de vinhaça e Corynebacterium glutamicum, em melaço a $10 \%$ e vinhaça bruta de cana-de-açúcar. Todos os microrganismos apresentaram crescimento tanto em melaço quanto em vinhaça. Em vinhaça bruta, a levedura que apresentou maior crescimento foi R. mucilaginosa, com 7,05 g/L; em meio de melaço foi $C$. lipolytica, com uma produção de biomassa de $6,09 \mathrm{~g} / \mathrm{L}$. O maior teor protéico da biomassa em vinhaça foi obtido por S. cerevisiae (50,35\%) e em melaço por C. glutamicum (46,16\%). C. lipolytica e R. mucilaginosa foram as leveduras que apresentaram a maior produção de lipídios, acima de $20 \%$ e 18\%, respectivamente, tanto em melaço quanto em vinhaça.
\end{abstract}

Palavras-chave: Microrganismos. Lipídeos. Proteínas. Melaço e vinhaça.

\begin{abstract}
This work evaluated the lipid and protein growth and synthesis capacity by Saccharomyces cerevisiae, Rhodotoruda mucilaginosa, Candida lipolytica, a yeast isolated from vinasse lakes and Corynebacterium glutamicum in 10\% molasses and sugar cane crude vinasse. All microorganisms grew both in molasses and vinasse. The highest growth in crude vinasse was performed by $R$. mucilaginosa (7.05 g/L), and in $10 \%$ molasses, by C. lipolytica, yielding 6,09 g/L. In vinasse, the highest protein content in the biomass was produced by $S$. cerevisiae ( $50.35 \%$ ) and in $10 \%$ molasses, by $C$. glutamicum (46,16\%). C. lipolytica and R. mucilaginosa showed the best lipid production, above $20 \%$ and $18 \%$, respectively, both in vinasse and in molasses.
\end{abstract}

Key words: Microorganisms. Lipids. Proteins. Molasses and vinasse.

\footnotetext{
Doutora em Ciências Biológicas.Departamento de Bioquímica e Microbiologia. Laboratório de Microbiologia Industrial Universidade Estadual Paulista / UNESP. Rio Claro - SP. E-mail: malulz@yahoo.com.br.

2 Docente do Departamento de Bioquímica e Biotecnologia - CCE/UEL. Universidade Estadual de Londrina/ UEL, Londrina-PR
} 


\section{Introdução}

O interesse por resíduos ou subprodutos industriais vem aumentando, devido à utilização dos mesmos como substrato para produção de proteína microbiana ou "single cell protein", um produto com elevado valor nutricional (NAVARRO; SEPÚLVEDA; RUBIO, 2000; EMTIAZI; ETEMADIFAR; TAVASSOLI, 2003; PARASKEVOPOULOU et al., 2003).

Entre os subprodutos mais abundantes, podem ser citados: o soro de queijo ou de leite (PARASKEVOPOULOU et al., 2003), e os resíduos da produção do glutamato (ZHENG et al., 2005), material celulósico de origem vegetal (DIAZ et al., 2003). Também merecem realce o melaço e a vinhaça de cana-de-açúcar, que podem ser empregados para o desenvolvimento de produtos biotecnológicos de interesse industrial (ALTAF et al., 2005) por muitos microrganismos como leveduras, algas, fungos e bactérias (ARNOLD; KNAPP; JOHNSON, 2000; ANUPAMA; RAVINDRA, 2000). Além disso, há um crescente interesse por novas fontes de ácidos graxos essenciais e muita atenção tem sido voltada para os microrganismos denominados oleaginosos, que representam fontes de óleos e gorduras (RUPCIC; BLAGOVIC; MARIC, 1996; DYAL; NARINE, 2005).

O melaço é um subproduto da agroindústria, freqüentemente utilizado como substrato para a produção de etanol (JIMENEZ; BORJA; MARTÍN, 2004) pois, devido à presença de grande quantidade de açúcares fermentescíveis em sua composição, ele constitui uma boa fonte de carbono para o metabolismo microbiano. Além disso, em sua composição estão presentes nitrogênio, fosfatos, cálcio e magnésio bem como zinco, manganês, cobre e ferro (WALISZEWSKI; ROMERO; PARDIO, 1997; CORTÉZ; BROSSARD-PÉREZ, 1997), nutrientes importantes para o metabolismo celular.

A vinhaça, por sua vez, é o maior efluente da indústria do etanol, representando um grande problema ambiental. Este líquido escuro é produzido a uma taxa de 10 a 15 litros para cada litro de etanol, sendo composto principalmente de água e compostos orgânicos e inorgânicos (MENEZES, 1980; ANCIÃES, 1980; POLACK; DAY; CHO, 1981).

No Brasil, grande parte da vinhaça está sendo utilizada como fertilizante devido ao seu conteúdo em material orgânico e a elevada concentração de nutrientes como potássio e nitrogênio $\left(30 \mathrm{gKg}^{-1} \mathrm{de}\right.$ peso seco) (DIAZ et al., 2003). O problema ocorre quando alguns solos não respondem positivamente à aplicação desse material ácido (WARD, 1991; CORTEZ; BROSSARD PEREZ, 1997), o que reduz a alcalinidade do solo e prejudica a colheita (KUMAR; VISWANATHAN, 1991), e essa causa deficiência em manganês no solo (AGRAWAL; PANDEY, 1994) e inibe a germinação de sementes (KANNABIAN; PRAGASAN, 1993).

Assim, o presente trabalho teve por objetivo estudar a aplicabilidade do melaço e vinhaça de canade-açúcar como substrato para produção de proteínas e lipídios de origem microbiana por quatro leveduras e uma bactéria.

\section{Material e Métodos}

Microrganismo: Foram utilizadas as leveduras Candida lipolytica, Rhodotorula mucilaginosa, Saccharomyces cerevisiae e a bactéria Corynebacterium glutamicum. As culturas foram mantidas em meio sólido (meio de preservação) sob temperatura de $4^{\circ} \mathrm{C}$, e renovadas a cada quatro semanas.

Meio de preservação: as culturas foram mantidas em meio sólido YEPD (yeast extract peptone dextrose) composto de (g/L): extrato de levedura 5,0; peptona 5,0; glicose 10,0; fosfato dibásico de potássio 0,5; ágar 20,0.

Meio de adaptação: antes de iniciar os cultivos, os microrganismos foram cultivados em meio contendo $(\mathrm{g} / \mathrm{L})$ : extrato de levedura 5,0; peptona 5,0; sacarose 10,0 e fosofato dibásico de potássio 0,5 .

Meios de cultivo: Utilizaram-se, como meios de cultivo, melaço e vinhaça bruta cana-de-açúcar, 
cedidos pela Cooperativa Agrícola de Rolândia COROL - Paraná, Brasil.

Inóculo e fermentações: O inóculo foi mantido em mesa agitadora "over night" a 180rpm sob temperatura de $28 \pm 2^{\circ} \mathrm{C}$. As fermentações foram realizadas em frascos de $250 \mathrm{~mL}$ contendo $50 \mathrm{~mL}$ de meio de cultivo, $28 \pm 2{ }^{\circ} \mathrm{C}$ e agitação de $180 \mathrm{rpm}$. Para os cultivos, a vinhaça foi utilizada na forma bruta, que apresentou cerca de $2 \%$ de açúcares redutores totais. O melaço foi diluído até a concentração de $10 \%$ de açúcares redutores totais. Os ensaios foram realizados em duplicata.

\section{Métodos analíticos:}

Determinação da proteína total: $\mathrm{O}$ teor de proteína total foi expressa como nitrogênio total $(\mathrm{N})$ multiplicado por 6,25 . O nitrogênio total foi determinado pelo método de Kjeldahl, de acordo com Association of Official Analytical Chemists (1984). Após a lavagem, a biomassa foi seca em estufa a $105^{\circ} \mathrm{C}$, até o peso constante, e quantificada por diferença de peso. Os cálculos foram realizados através de fatores obtidos de uma curva de calibração cuja densidade óptica (DO) foi correlacionada com o peso seco.

Determinação dos açúcares redutores totais (ART): Os açúcares redutores totais (ART) foram determinados, após hidrólise com $\mathrm{HCl} 2 \mathrm{M}$ e neutralizados com $\mathrm{NaOH} 2 \mathrm{M}$, pelo método de Somogy (1945) e Nelson (1944).

Extração e determinação dos lipídios totais:Para a extração dos lipídios foram utilizados $10 \mathrm{~g}$ de biomassa lavada com metanol:clorofórmio 1:1(v/v) em aparelho Soxhlet durante 13 horas. Em seguida, os solventes foram retirados por evaporação em rota-vapor a $70^{\circ} \mathrm{C}$; a camada lipídica retida no fundo do frasco foi retirada com metanol:clorofórmio 1:1 ( $/ \mathrm{v})$, transferida para tubos de ensaio e os solventes novamente evaporados. Em seguida, os lipídios foram determinados pelo método de Frings e Dunn (1970).

\section{Resultados e Discussão}

Produção de biomassa e proteína em vinhaça bruta

A produção de biomassa e proteínas pelas leveduras e pela bactéria $C$. glutamicum em vinhaça está descrita nas Figuras 1A e 1B, respectivamente. A maior produção de biomassa foi obtida por $R$. mucilaginosa, 7,05g/L. C. lipolytica e apresentou um conteúdo de proteína pouco acima de 5,0 g/L. Embora a produção de biomassa por $S$. cerevisiae tenha sido de apenas 4,55 g/L, a maior produção de proteína da biomassa foi atingida por esta levedura, $2,29 \mathrm{~g} / \mathrm{L}$, o que correspondeu a 50,35\%. Esse resultado é comparável pois com os encontrados na literatura, na qual os resultados da produção de biomassa por leveduras se encontra entre 50-70\% (ANUPAMA; RAVINDRA, 2000). R. mucilaginosa atingiu um conteúdo protéico um pouco maior, de 2,43 g/L.

As bactérias também despertam interesse por apresentarem biomassa com altos valores nutritivos, além de alta velocidade de crescimento e elevado conteúdo protéico, variando de 47 a $87 \%$ (BU'LOCK; KRISTIANSEN, 1991). Além disso, segundo Dabbah (1970), metionina, triptofano e cistina, que são aminoácidos deficientes em leveduras e fungos, podem ser encontrados nas proteínas de bactérias. Neste trabalho, a menor produção de biomassa foi obtida pela bactéria C. glutamicum, 3,46 g/L, embora sua biomassa tenha apresentado um bom conteúdo protéico, $41,96 \%$. 


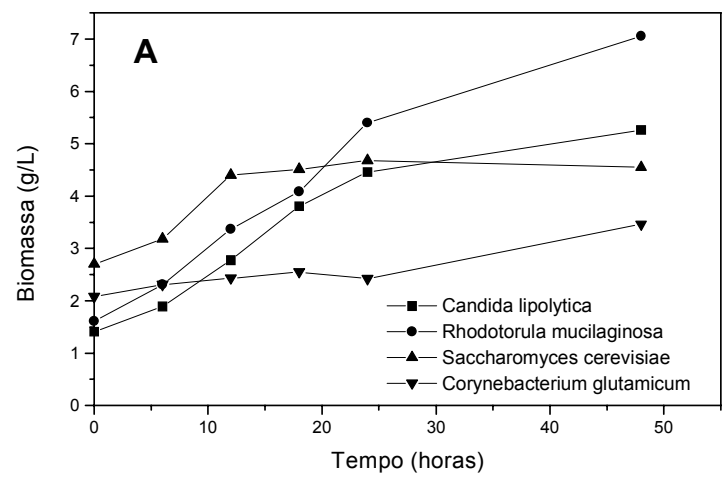

Figura 1.A) Produção de biomassa (g/L)

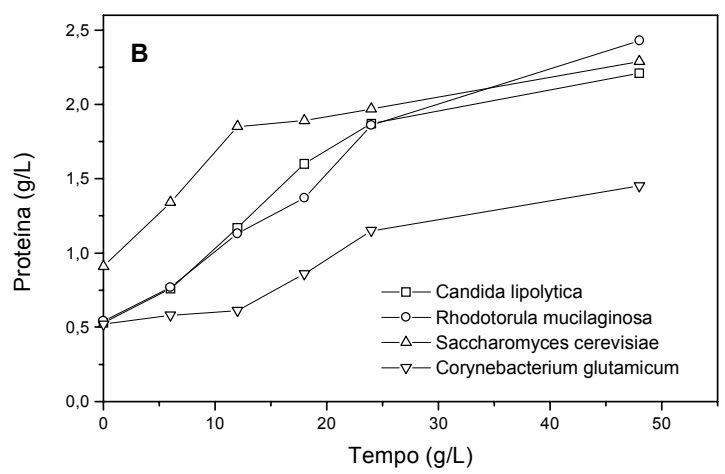

Figura 1.B) Produção de proteína (g/L) das leveduras e da bactéria em vinhaça bruta.

A produção de biomassa acompanhou o consumo de açúcares do meio, eC. lipolytica, $R$. mucilaginosa e $S$. cerevisiae consumiram acima de 50,0\%. A bactéria C. glutamicum consumiu 39,8\% e a levedura isolada, 27,19\% (Figura 2).

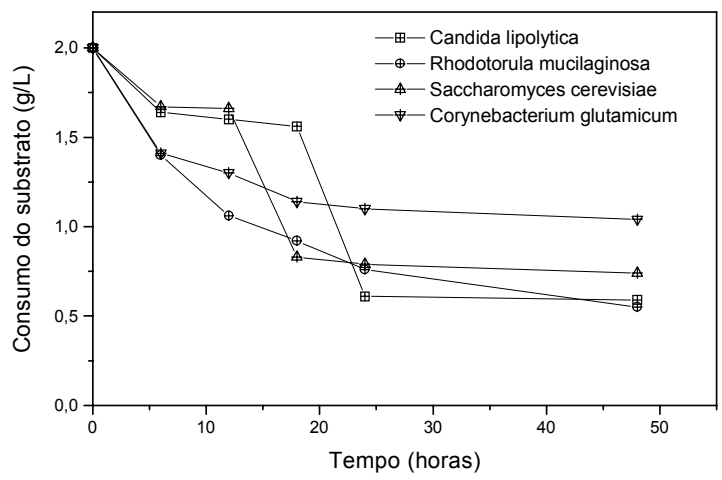

Figura 2: Consumo de substrato pelas leveduras e bactéria em meio de vinhaça bruta após 48 horas.
Produção de biomassa e proteína em melaço a 10\%

Em meio de melaço, $C$. lipolytica foi a levedura que apresentou a maior produção de biomassa, 6,28 $\mathrm{g} / \mathrm{L}$, seguida por $S$. cerevisiae com $5,46 \mathrm{~g} / \mathrm{L}$. A bactéria $C$. glutamicum atingiu $2,79 \mathrm{~g} / \mathrm{L}$ de biomassa; R. mucilaginosa produziu apenas 1,62 g/L (Figura $3 \mathrm{~A})$

A maior produção de proteína na biomassa foi obtida por C. lipolytica, 2,11 g/L. A levedura $S$. cerevisiae e a bactéria $C$. glutamicum produziram pouco acima de $1,0 \mathrm{~g} / \mathrm{L}$ e $R$. mucilaginosa apenas $0,68 \mathrm{~g} / \mathrm{L}$ (Figura 3B).

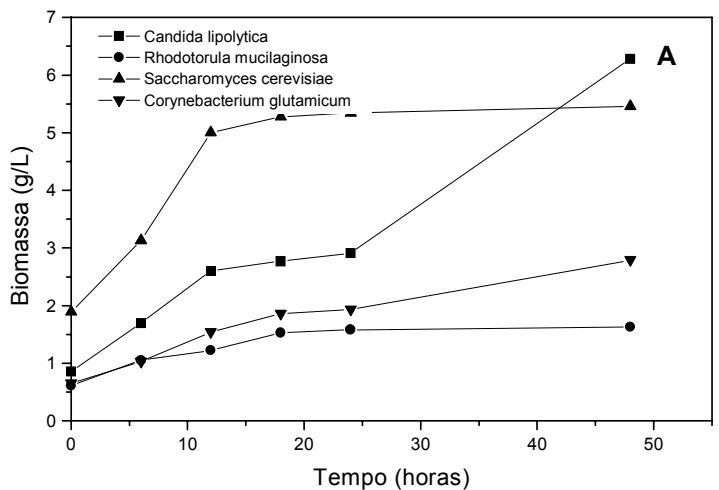

Figura 3. A) Produção de biomassa (g/L)

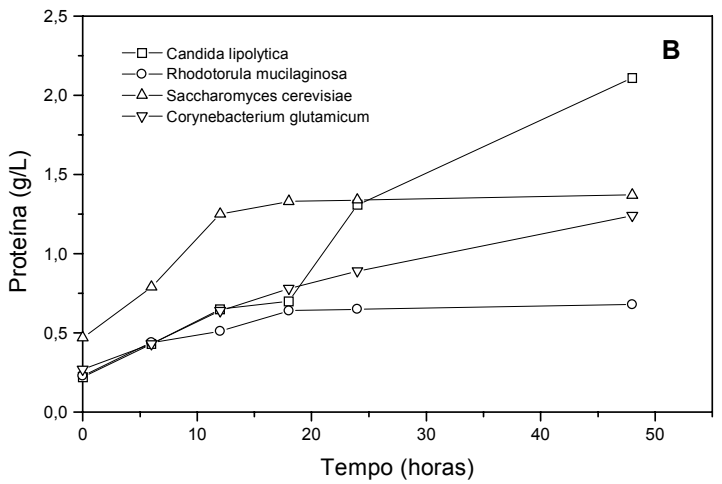

Figura 3. B) Produção de proteína (g/L) pelas leveduras e bactéria em melaço a $10 \%$.

O consumo de açúcares foi pequeno no meio de melaço, apresentando valores abaixo de $10 \%$ para C. lipolytica e C. glutamicum; R. mucilaginosa 
consumiu 11,30\%. Apenas $S$. cerevisiae apresentou um consumo elevado, $96,52 \%$, mas que não refletiu na produção de proteínas ou lipídios (Figura 4). Esse comportamento pode ter ocorrido devido aos sais e outras substâncias presentes no melaço, que afetam o crescimento de alguns microrganismos.

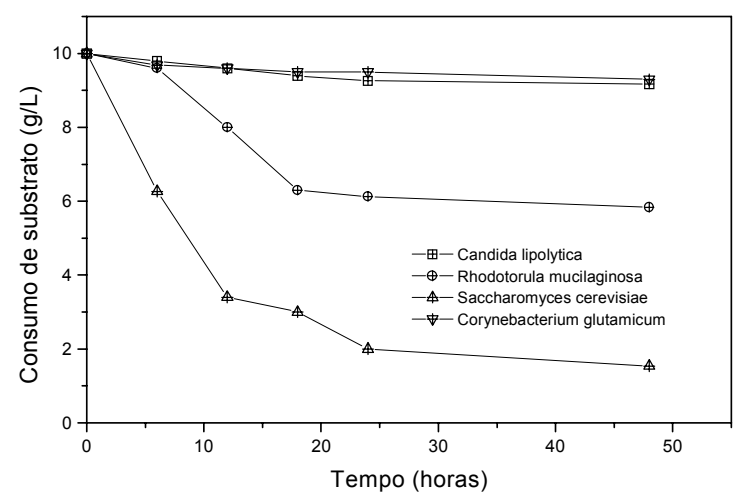

Figura 4. Consumo de substrato $(\mathrm{g} / \mathrm{L})$ pelas levedura e bactéria em melaço a 10\% após 48 horas.

\section{Produção de lipídeos}

Segundo Ratledge (1996), as principais classes de microrganismos utilizados para a produção de lipídios, considerados microrganismos oleaginosos, são as leveduras e os fungos; estes podem produzir até $40 \%$ de sua biomassa em lipídios. Porém, bactérias e algas também são potencialmente produtivas. Para que um microrganismo seja candidato favorável aos interesses comerciais, deve apresentar de 20-25\% de lipídios em sua biomassa. Sendo assim, pode-se considerar como oleaginosas as leveduras $C$. lipolytica e $R$. mucilaginosa (Tabela 4), que apresentaram as maiores produções de lipídios, acima de $20 \%$ e $18 \%$, respectivamente, seguidas por $S$. cerevisiae que apresentou uma produção lipídida em torno de 11\%. Essas leveduras produziram quantidades similares de lipídios tanto em melaço quanto em vinhaça. No meio de melaço, o conteúdo lipídico da biomassa da bactéria C. glutamicum duplicou, atingindo 15,87\%. Esse valor é superior ao descrito para outras bactérias como B. subtilis, $B$. cereus e E. coli, 8 a 8,5\% (KURBANOGLU; ALGUR, 2002).

Tabela 1: Produção de lipídios pelas leveduras e bactéria em vinhaça e melaço de cana-de-açúcar após 48 horas de cultivo.

\begin{tabular}{l|c|c|c|c}
\hline \multicolumn{1}{c|}{ Microrganismo } & \multicolumn{2}{|c|}{ Vinhaça } & \multicolumn{2}{c}{ Melaço } \\
\hline & $\begin{array}{c}\text { Lipídios } \\
\mathbf{( \% )}\end{array}$ & $\begin{array}{c}\text { Lipídios } \\
\mathbf{( g / L )}\end{array}$ & $\begin{array}{c}\text { Lipídios } \\
\mathbf{( \% )}\end{array}$ & $\begin{array}{c}\text { Lipídios } \\
\mathbf{( g / L )}\end{array}$ \\
\hline Candida lipolytica & 21,16 & 0,40 & 25,59 & 0,71 \\
\hline Rhodotorula mucilaginosa & $18, .38$ & 0,62 & 18,80 & 0,60 \\
\hline $\begin{array}{l}\text { Saccharomyces cerevisiae } \\
\text { glutamicum }\end{array}$ & 12,31 & 0,58 & 10,78 & 0,53 \\
\hline
\end{tabular}

O estudo de microrganismos para a produção de lipídios é alternativa para a substituição de fontes convencionais de óleos e gorduras. Uma vez que estes lipídios apresentam composição semelhante aos óleos vegetais, poderiam ser empregados para fins alimentares, combustíveis alternativos, bem como na produção de compostos específicos de uso limitado, como produtos farmacêuticos (CELLIGOI, 1993).
Considerando a importância da fonte de carbono utilizada, bem como a aplicação de subprodutos agroindustriais, o melaço de cana de açúcar tem sido alvo de vários estudos na produção de biomoléculas energéticas. Já Garcia, Angeles e Garrido (1956), avaliaram a possibilidade de emprego do melaço para a produção de lipídios por 22 espécies de Penicillium. Glatz, Floetenmeyer e Hammond (1985), 
preocupados com a utilização de resíduos, testaram Candida curvata em melaço na produção lipídica. Araújo (1997), comparou a produção lipídica de quatro linhagens de leveduras em meio de melaço com meios definidos como glicose e sacarose. $\mathrm{O}$ autor observou que os microrganismos em melaço apresentaram teores lipídicos que variaram entre 20 e $40 \%$ e foram superiores aos obtidos nos meios de glicose e sacarose.

\section{Conclusões}

Para a levedura $R$. mucilaginosa, o meio de vinhaça bruta foi mais favorável para as produções de biomassa e de proteína, sendo $77,0 \%$ e $72,0 \%$ maiores, respectivamente, quando comparadas com o meio de melaço. Para C. lipolytica, S. cerevisiae e C. glutamicum ocorreram produções similares de biomassa tanto em vinhaça quanto em melaço. No entanto o conteúdo protéico da biomassa de $S$. cerevisiae foi $40 \%$ maior em vinhaça bruta. A produção de lipídios totais foi similar em ambos os substratos, com exceção de C. glutamicum que apresentou uma produção lipídica 2,57 vezes maior em vinhaça bruta.

\section{Referências}

AGRAWAL, C.; PANDEY, G. Soil pollution by spent wash discharge: depletion of manganese. Journal of Environmental Biology, India, v.15, n.1, p.49-53, 1994.

ALTAF, M. D.; NAVEENA, B. J.; VENKATESHWAR, M.; KUMAR, E. V.; REDDY, G. Single step fermentation of starch to $\mathrm{L}(+)$ lactic acid by Lactobacillus amylophilus GV6 in SSF using inexpensive nitrogen sources to replace peptone and yeast extract - optimization by RSM. Process Biochemistry, London, v.41, n.2, p.465-472, Feb. 2006.

ANCIÃES, A. W. Avaliação tecnológica do álcool etílico. 3 ed. Brasília: Editorial do CNPq, 1981.

ANUPAMA, M., RAVINDRA, P. Value-added food: single cell protein. Biotechnology Advances, New York, v.18, n.6, p.459-479, 2000.

ASSOCIATION OF OFFICIAL ANALYTICAL CHEMISTS. Methods of Analysis. 13. ed. Washington, 1984.
ARAÚJO, A. K. V. Avaliação da produção de lipídios de leveduras em meio de glicose, sacarose e melaço de cana-de-açicar. 1997. Monografia (Especialização em Bioquímica Aplicada) - Universidade Estadual de Londrina, Londrina.

ARNOLD, J. L.; KNAPP, J. S.; JOHNSON, C. L. The use of yeast to reduce the polluting potential of silage effluent. Water Research, New York, v.34, n.15, p. 3699-3708, 2000.

BU'LOCK, J., KRISTIANSEN, B. Biotecnologia básica. Zaragoza: Acríbia, 1991.

CELligoI, M. A. P. C. Produção de triglicérides, fosfolipídios e esteróis por leveduras isoladas de diferentes nichos ecológicos. 1993. Tese (Doutorado em Ciências Biológicas) - Instituto de Biociências, Universidade Estadual Paulista "Júlio de Mesquita Filho", Rio Claro.

CORTEZ, L. A. B.; BROSSARD PÉREZ, L. E. Experiences On Vinasse Disposal Part III: Combustion of Vinasse-\# 6 Fuel Oil Emulsions. Brazilian Journal of Chemical Engineering, São Paulo, v.14, n.1, 1997.

DABBAH, R. Protein from microorganisms. Food Technology, Chicago, v.24, n.6, p.569-666, 1970.

DIAZ, M. J.; EUGENIO, M. E.; JIMÉNEZ, L.; MADEJÓN, E.; CABRERA, F. Modelling vinasse/ cotton waste ratio incubation for optimum composting. Chemical Engineering Journal, Lausanne, v.93, n.3, p.233-240, 2003.

DYAL, S. D.; NARINE, S. S. Implications in the use of Mortirella fungi in the industrial production of essential fatty acids. Food Research International, Barking, v.38. p.445-467, 2005.

EMTIAZI, G.; ETEMADIFAR, Z.; TAVASSOLI, M. A novel nitrogen-fixing cellulytic bacterium associated with root of corn is a candidate for production of single cell protein. Biomass and Bioenergy, Oxford, v.25, p.423-426, 2003.

FRINGS, C. S.; DUNN, R. T. A colorimetric method for determination of serum lipids based on the sulphophospho-vanilin reaction. American Journal of Clinical Pathology, Philadelphia, v.53, n.1, p.89-91, 1970.

GARCIA, R. P., ANGELES, S. L., GARRIDO, J. M. Lipid production of microrganisms: the lipid-synthesing capacity of 22 species of Penicillium. Revista de Ciencia Aplicada, Madrid, v.10, p.13-21, 1956.

GLATZ, B. A., FLOETENMEYER, D., HAMMOND, E. G. Fermentation of bananas and other food wastes to produce microbial lipid. Journal of Food Protection, Des Moines, v.48, n.7, p.574-577, 1985.

JIMENEZ, A. M; BORJA, R.; MARTÍN, A. A comparative kinetic evaluation of the anaerobic digestion untreated molasses and molasses previously fermented Penicillium decumbens in batch reactors. Biochemical Engineering Journal, Amsterdam, v.18, n.2, p.121-132, 2004. 
KANNABIRAN, B.; PRAGASAN, A. Effect of destillery effluent on seed germintation, seeding growth content of Vigna mugno. Geobios, Lyon, v.20, p.108-112, 1993.

KUMAR, S.; VISWANATHAN, L. Production of biomass, carbon dioxide, volatile acids, during distillery waste treatment by bacterial strains. Enzyme Microbial Technology, New York, v.13, n.2, p.179-187, 1991.

KURBANOGLU, E. B., ALGUR, O. F. Single-cell protein production from ram horn hydrolysate by bacteria. Bioresource Technology, Essex, v.85, n.2, p.125-129, 2002.

MENEZES, T. J. B. Etanol: o combustível do Brasil. São Paulo: Agronômica Ceres, 1980.

NAVARRO, A. R.; SEPÚLVEDA, M. C.; RUBIO, M. C. Bioconversion of vinasse from alcoholic fermentation of sugar cane molasses. Waste Management, Oxford, v.20, p.581585,2000 .

NELSON, N. A. A photometric adaptation of Somogy method for determination of glucose. Biochemistry, New York, v.153, p.375-380, 1944.

PARASKEVOPOULOU, A.; ATHANASIADIS, I.; KANELLAKI, M.; BEKATOROU, A.; BLEKAS, G.; KIOSSEOGLOU, V. Functional properties of single cell protein produced by Kefir microflora. Food Research International, Barking, v.36, n.5, p.431-438, 2003.
POLACK, J. A.; DAY, D. F.; CHO, Y. K. Gasohol from Sugarcane-Stillage Disposition. Louisiana: Audubon Sugar Institute, 1981.

RATLEDGE, C. Microrganisms for lipids. In: MEESTERS, P. A.; HUIJBERTS, G. N. High-cell density cultivation of the lipid accumulating yeast Cryptococcus curvatus using glycerol as a carbon source. Applied Microbiology Biotechnology, v.45, n.5, p.575-579, 1996.

RUPCIC, J.; BLAGOVIC, B.; MARIC, V. Cell lipids of the Candida lipolytica yeast grown on methanol. Journal of Chromatography A., Amsterdam, v.755, n.1, p.75-80, 1996.

SOMOGY, M. A. A new reagent for determination of sugar. Journal of Biology Chemistry, v.160, p.61-68, 1945.

WALISZEWSKI, K. N.; ROMERO, A.; PARDIO, V. T. Use of cane condensed molasses in feeding broilers. Animal Feed Science Technology, Amsterdam, v.67, p.253-258, 1997.

WARD, O. P. Biotecnologia de la fermentacion. Zaragoza: Acríbia, 1991.

ZHENG, S.; YANG, M.; YANG, Z.; YANG, Q. Biomass production from glutamate fermentation wastewater by co-culture of Candida halophila and Rhodotorula glutinis. Bioresource Technology, Essex, v.96, n.13, p. 1522-1524, 2005. 
